\title{
A POLÍTICA DA MORTE: UMA ANÁLISE SOBRE A SUBJUGAÇÃO DO DIREITO A VIDA PELO PODER ESTATAL, SOB O APORTE TEÓRICO DE ACHILLE MBEMBE
}

Fernando Campos Nazaré

Graduando em Direito pela Universidade da Amazônia - UNAMA. E-mail: fcdireitoacademico@gmail.com

\section{RESUMO}

O Estado, ao longo dos tempos históricos de final do período medieval, da modernidade e da pós modernidade, se (re)configurou de diversas formas. Esta estrutura máxima civilizacional foi se modificando e se tornando cada fez mais soberana e interferindo sobremaneira na vida daqueles que devam ser adeptos dessa organização vital da sociedade. O poder estatal, dessa forma, tem toda a legitimidade de dar o direcionamento de todos os setores públicos: como será organizada a saúde e a educação de modo a promover o bem-estar à todas e todos; como implementará os mecanismos de segurança pública diante da possibilidade de violência entre os cidadãos e, nesse sentido, formular normas de conduta social e jurídica de resguardo a paz social, entre outros tantos deveres na qual ao Estado é atribuído. Todavia, esse poder que deveria ser apenas uma responsabilidade de gestacionar positivamente a vida na sociedade vai agir, na realidade, como uma soberania tirana quando também determinará que o bem jurídico-social de maior importância, que é a vida, será 'direito' apenas para alguns. Entendemos então que, desde a concepção de Estado Moderno, tem-se a ideia de legitimação deste como controlador da vida de seus adeptos. Entretanto, este também será o determinante daquele ser social que não poderá viver e deverá ser sacrificado por conta do atual modelo seletivo sócio-punitivo. Quem deve morrer e quem pode viver? Essa indagação será respondida com base na luta de classes sociais, pois aqueles que detém o capital financeiro e se assemelham ao padrão europeu de branquitude serão quem deveram viver e, aquele desprovidos de recursos materiais e estigmatizados racialmente serão os mortos pela soberania estatal, que direta ou indiretamente causará a mortalidade de grupos de indivíduos de determinada classe social, a população pobre - e negra. Levantar reflexões a respeito da problemática da Necropolítica como método de biopoder estatal na punição letal e perpétua da classe periférica da sociedade é, de maneira sucinta, o objetivo e a finalidade deste trabalho de pesquisa, que não pretenderá exaurir na sua conclusão, mas enriquecer os estudos do referido dilema. Num primeiro momento será realizado um 
diagnóstico basilar sobre conceitos, objetivos e finalidades do estudo sobre a política da morte e como este instrumento utilizado pelo Estado causa a violação do bem jurídico mais importante, a vida. Buscou-se para ser utilizado como aporte teórico da problemática refletida os estudos acerca da Necropolítica de Achille Mbembe de modo a entender os meandros de toda essa peculiaridade em relação a política da morte. Para isso, na conclusão do referido trabalho descreveremos brevemente o que moradores de um bairro periférico do município de Belém têm feito para modificar o olhar em relação a população pobre da cidade, criando um coletivo que tem com objetivo quebrar estereótipos que recaem sobre a pobreza.

PALAVRAS-CHAVE: Política da Morte. Poder Estatal. Achille Mbembe.

\title{
THE POLITICS OF DEATH: AN ANALYSIS ON THE SUBJUGATION OF THE RIGHT TO LIFE BY STATE POWER, UNDER THE THEORETICAL SUPPORT OF ACHILLE MBEMBE
}

\begin{abstract}
The State, throughout the historical times of the late medieval period, of modernity and post-modernity, has (re) configured itself in several ways. This maximum civilizational structure has been changing and becoming more and more sovereign and interfering greatly in the lives of those who must be adepts in this vital organization of society. Thus, state power has every legitimacy to give direction to all public sectors: how health and education will be organized in order to promote the well-being of all; how it will implement public security mechanisms in the face of the possibility of violence among citizens and, in this sense, formulate rules of social and legal conduct to safeguard social peace, among many other duties to which the State is assigned. However, this power, which should only be a responsibility to positively manage life in society, will act, in reality, as a tyrant sovereignty when it will also determine that the most important legal and social asset, which is life, will only be 'right'. for some. We understand then that, since the conception of the Modern State, we have the idea of legitimizing it as the controller of the life of its followers. However, this will also be the determinant of that social being who will not be able to live and must be sacrificed due to the current selective socio-punitive model. Who should die and who can live? This question will be answered based on the struggle of social classes, because those who own the financial capital and resemble the European standard of whiteness will be the ones who should have lived, and those without material resources and racially stigmatized will be the ones killed by state sovereignty, which directly or indirectly it will cause the mortality of groups of individuals of a certain social class, the poor - and black population. Raising reflections on the problem of Necropolitics as a method of state
\end{abstract}


biopower in the lethal and perpetual punishment of the peripheral class of society is, in a succinct way, the objective and purpose of this research work, which will not intend to exhaust in its conclusion, but enrich the studies of the said dilemma. At first, a basic diagnosis will be carried out on the concepts, objectives and purposes of the study on death policy and how this instrument used by the State causes the violation of the most important legal asset, life. The studies on Achille Mbembe's Necropolitics were sought to be used as a theoretical contribution to the problems reflected in order to understand the intricacies of all this peculiarity in relation to the politics of death. For this purpose, at the conclusion of this work, we will briefly describe what residents of a peripheral neighborhood in the municipality of Belém have been doing to modify their view of the city's poor population, creating a collective that aims to break stereotypes that fall on poverty.

KEYWORDS: Death Policy. State Power. Achille Mbembe.

\section{INTRODUÇÃO}

O Estado, ao longo dos tempos históricos de final do período medieval, da modernidade e da pós modernidade, se (re)configurou de diversas formas. Esta estrutura máxima civilizacional foi se modificando e se tornando cada fez mais soberana e interferindo sobremaneira na vida daqueles que devam ser adeptos dessa organização vital da sociedade. O poder estatal, dessa forma, tem toda a legitimidade de dar o direcionamento de todos os setores públicos: como será organizada a saúde e a educação de modo a promover o bem-estar à todas e todos; como implementará os mecanismos de segurança pública diante da possibilidade de violência entre os cidadãos e, nesse sentido, formular normas de conduta social e jurídica de resguardo a paz social, entre outros tantos deveres na qual ao Estado é atribuído. Todavia, esse poder que deveria ser apenas uma responsabilidade de gestacionar positivamente a vida na sociedade vai agir, na realidade, como uma soberania tirana quando também determinará que o bem jurídico-social de maior importância, que é a vida, será 'direito' apenas para alguns.

Entendemos então que, desde a concepção de Estado Moderno, tem-se a ideia de legitimação deste como controlador da vida de seus adeptos. Entretanto, este também será o determinante daquele ser social que não poderá viver e deverá ser sacrificado por conta do atual modelo seletivo sócio-punitivo. Quem deve morrer e quem pode viver? Essa indagação será respondida com base na luta de classes sociais, pois aqueles que detém o capital financeiro e se assemelham ao padrão europeu de branquitude serão quem deveram viver e, aquele desprovidos de recursos materiais e estigmatizados racialmente serão os mortos pela soberania estatal, que direta ou indiretamente causará a mortalidade de grupos de indivíduos de Complexitas - Rev. Fil. Tem., Belém, v. 4, n. 2 , p. 19-26, jul./dec. 2019 - ISSN: 2525-4154 
determinada classe social, a população pobre - e negra.

Levantar reflexões a respeito da problemática da Necropolítica como método de biopoder estatal na punição letal e perpétua da classe periférica da sociedade é, de maneira sucinta, o objetivo e a finalidade deste trabalho de pesquisa, que não pretenderá exaurir na sua conclusão, mas enriquecer os estudos do referido dilema. Num primeiro momento será realizado um diagnóstico basilar sobre conceitos, objetivos e finalidades do estudo sobre a política da morte e como este instrumento utilizado pelo Estado causa a violação do bem jurídico mais importante, a vida. Buscou-se para ser utilizado como aporte teórico da problemática refletida os estudos acerca da Necropolítica de Achille Mbembe de modo a entender os meandros de toda essa peculiaridade em relação a política da morte. Para isso, na conclusão do referido trabalho descreveremos brevemente o que moradores de um bairro periférico do município de Belém têm feito para modificar o olhar em relação a população pobre da cidade, criando um coletivo que tem com objetivo quebrar estereótipos que recaem sobre a pobreza.

\section{COMPREENDER O ESTUDO DA NECROPOLÍTICA}

O estudo da política da morte tangencia sobre vários conceitos e definições que estão relacionados ao poder, e não qualquer poder, mas aquele que determinará quem vive e quem morre, quem mata e quem deixa viver; como se legítima tal poder supremo? É necessário, num primeiro plano, a demonstração de termos importantes para a análise de um bom estudo sobre vida/morte.

A noção de biopoder, aliado ao de soberania, é a forma insuficiente da contemporaneidade de subjugar a vida ao poder da morte (Mbembe, 2016: 146), ou seja, ter o poder sobre a vida é utilizado para ditar o fim desta. Neste sentido, se há um poder sobre a morte, recorremos por explicar as noções de necropolítica e necropoder que servem "para explicar as várias maneiras pelas quais, em nosso mundo contemporâneo, armas de fogo são implantadas no interesse de destruição máxima de pessoas e da criação de 'mundos de morte", em que "formas novas e únicas da existência social, nas quais vastas populações são submetidas a condições de vida que lhes conferem o status de "mortos-vivos"' (Mbembe, idem)

Michel Foucault (1997) entende que por biopoder tem-se um domínio da vida sobre o qual um determinado poder tomou controle e poderá retirá-la de cena. Para ele a soberania de 
matar é exercida pelo Estado para que este possa se manter como controlador das "vidas" das pessoas em sociedade. O Estado é quem decide, por meio do biopoder, as pessoas que deveram viver e as pessoas que deveram morrer.

Para Hannah Arendt, "não existem paralelos a vida nos campos de concentração. Seu horror não pode ser inteiramente alcançado pela imaginação, justamente por situar-se fora da vida e da morte" (Arendt, 1996: 444). A autora explica a política da morte por base nos estudos a respeito dos Estados Nazista e Totalitarista que utilizavam campos de concentração/extermínio para empreender o seu biopoder causando a violência mortal contra o povo judeu.

Chegamos então ao que o historiador camaronês Achille Mbembe compila por meio das expressões de biopoder, estado de exceção, política da morte e necropolitica, o poder da morte e da vida relacionados a soberania de quem exerce tal poder e "pressupõe que a expressão da soberania reside, em grande medida, no poder e na capacidade de ditar quem pode viver e quem deve morrer. Por isso, matar ou deixar viver constituem os limites da soberania, seus atributos fundamentais". Mbembe conclui que "exercitar a soberania é exercer o controle sobre a mortalidade e definir a vida como a implantação e manifestação de poder" (Mbembe, 2016: 123)

\section{COMPREENSÃo PRÁticA SOBRE A POLITICA DA MORTE PELO PODER ESTATAL}

Em Belém do Pará, assim como em outras metrópoles brasileiras, a Necropolítica é empreendida contra a população que fica às margens dos grandes centros urbanos, as periferias. Daí é interessante notar que a capital paraense apresenta especificidades do modo que a política da morte se legítima. Há todo um enredo digno de filmes, com cenário, atores e roteiros originais que acarretaram na retirada da vida, tornando culturalmente únicos os crimes de morte em série nas periferias da Região Metropolitana de Belém.

É comumente veiculado em programas policiais de TV pseudojornalísticos inúmeros casos de crimes cometido por pessoas que são referenciadas como inimigos de toda a sociedade, essa é um ideia de que há uma guerra constante entre a "bandidagem" e a polícia. Essa narrativa que visa o lucro causa a luta entre os membros da periferia onde aqueles que se consideram 'cidadãos-de-bem' apropriam-se de um discurso ditado pelos soberanos - o Estado e a classe dominante - contra aqueles 'cidadãos-do-mal'. Ou seja, os detentores da soberania 
subjugam a população periféricas com auxílio desta para a produção de suas mortes.

Somente no período de $1^{\circ}$ à 8 de janeiro de 2018 foram registradas 118 mortes violentas no estado do Pará, o que ao longo do ano o índice de homicídio aumentou drasticamente. O número total de homicídios no estado, de $1^{\circ}$ de janeiro até dia 6 de novembro, foi de 3.168, segundo dados apresentados pela Secretaria de Estado de Segurança Pública e Defesa Social (Segup) em audiência convocada pela Comissão de Direitos Humanos (CDH), da Assembleia Legislativa do Pará (Alepa). De acordo com estatísticas fornecidas pelo site Justificando, considerando o período entre 8 e 13 de Abril de 2018, os números são catastróficos, pois a cidade de Belém registrou 72 homicídios, e além disso 22 pessoas (21 presos) foram mortas no presídio de Santa Izabel, região metropolitana. Em outubro, após outra chacina - duas já haviam sido registradas na grande Belém e outra em Pau D'Arco, interior do estado -, contabilizou-se que 10 pessoas são mortas por dia no estado do Pará até aquele momento no ano de 2018. Só a cidade de Belém registrou, segundo dados da Secretaria de Segurança Pública - Segup, 793 homicídios dolosos e em Ananindeua foram 341, o que é desmentido com pesquisas feitas pela Sociedade Paraense de Direitos Humanos - SDDH, que tais números têm uma discrepância de quase 100 mortes à mais do que divulgada pela secretaria, sem contar que não foram contabilizados os registros de mortes cometidos por policiais e agentes de segurança pública que são contabilizados apenas como mortes isoladas em confronto contra a polícia.

\section{A NECROPOLÍTICA DE ACHILLE MBEMBE: COMPREENSÃO TEÓRICA}

Cabe, neste momento, uma compreensão universalista a respeito do "direito de matar" a qual os Estados nacionais se legitimam. Para isso, buscamos por uma vertente da sociologia jurídica e de direito internacional dos direitos fundamentais (ou direitos humanos, se levarmos em conta a analise universalista) a partir da filosofia do autor camaronês Achille Mbembe, que traz esclarecimentos ímpares da problemática trazida.

Logo de início, em seu ensaio sobre a Necropolítica ele reflete sobre a singularidade do extermínio dos judeus em campos de concentração e que é um ponto importante de se fazer uma análise sobre a fabricação de mortes a seletas pessoas que estão condicionadas a se desfazerem do direito à vida por conta de uma política estatal cruel e letal. Mbembe traz à luz como esse grupo social marginalizados - os judeus - quando durante a predominância do Nazismo eram aglutinados nesse lugar extremamente atroz. Trazendo para a realidade 
belenense, esse lugar de extermínio são as periferias da região metropolitana da capital paraense (lócus da pesquisa), que são espaços escassos de saneamento básico, de educação e de saúde eficazes aos anseios dessa população que são pobres e em sua maioria de cor de pele negra.

Por conseguinte, o autor traz a questão da soberania como uma política de biopoder estatal e para isso, recorre a Foucault para explicitar os meandros desse processo tirano do Estado. Dessa forma, Mbembe evidência quando:

Foucault afirma claramente que o direito soberano de matar (droit de glaive) e os mecanismos de biopoder estão inscritos na forma em que funcionam todos Estados modernos; de fato, eles podem ser vistos como elementos constitutivos do poder do Estado na modernidade. Segundo Foucault, o Estado nazista era o mais completo exercendo o direito de matar. Esse Estado, afirma ele, tornou a gestão, proteção e cultivo da vida coextensivo ao direito soberano de matar. Por uma extrapolação biológica sobre o tema do inimigo político, na organização da guerra contra os seus adversários e, ao mesmo tempo, expondo seus próprios cidadãos à guerra, o Estado Nazista é visto como aquele que abriu o caminho para uma tremenda consolidação do direito de matar, que culminou no projeto da "solução final". Ao fazê-lo, tornou-se o arquétipo de uma formação de poder que combinava as características de Estado racista, Estado assassino e Estado suicida. (MBEMBE, 2016: 128)

Nesse ínterim, o que nos parece é que os Estados na contemporaneidade tomam como exemplo o Estado nazista de modo a subjugar a vida seus cidadãos, aqueles citados escolhidos por estereótipos criados ao longo de um processo histórico desde a colonização brasileira em que se perdura até os dias atuais um mal de preconceitos e violência gerada pelo poder estatal.

\section{CONSIDERAÇÕES FINAIS}

Ante todo o exposto, faz-se necessário como resposta ao entendimento da complexidade da situação ora debatida entende-se que resistir é fundamental de modo a unificar as lutas contra o genocídio da população pobre, compreendendo o recorte de raça que é recaído àqueles que estatisticamente são os principais alvos desse sistema necropolítico da qual o Estado se apoia para se manter soberano.

Faremos referência a um coletivo do bairro Terra Firme, região periférica de Belém, que tem o intuito mudar a forma como o lugar é visto e mencionado nos grandes veículos de comunicação de massa - principalmente aqueles programas policialescos que já fora mencionado neste trabalho -, que em sua maioria, através das matérias divulgadas, criminalizam o bairro e seus moradores, o que acaba criando estereótipos de um espaço 
violento. Os seus idealizadores produziram um documentário mostrando a indignação da população periférica em relação das mortalidades de jovens e trazendo a retratação de quatro chacinas ocorrida de 1994 à 2014 na região metropolitana da capital, bem como mostrando as coisas e pessoas boas que fazem parte da periferia belenense. Por meio de produção audiovisual, o coletivo Tela Firme veicula seu material através das redes sociais (YouTube e Facebook), com o intuito de mostrar o que há de bom, os valores da periferia e a sintonia com os diversos movimentos sociais que atuam na defesa da vida e dos direitos humanos.

Como verificado durante todo o trabalho constatamos que o Estado não cumpre com seu dever de proteger a vida de seus cidadãos e cidadãs, mas é o causador do extermínio daqueles indivíduos em vulnerabilidade social e econômica. O breve relato feito sobre o Projeto Tela Firme nos mostra que em decorrência da indiferença e ação letal do Estado é necessário criar meios para que as populações de áreas marginalizadas se mantenham vivos e criem mecanismos de combate aos preconceitos que sofrem.

\section{REFERÊNCIAS BIBLIOGRÁFICAS}

ARENDT, Hannah. The origiuns of totalitarianism. New York: Harverst, 1966: 444.

FOUCAULT, Michel. Discipline and prinish: The birth of the prison. New York: Pantheon, 1977.

MAPA DA VIOLÊNCIA. Atlas da Violência de 2019. Disponível em: http://www.ipea.gov.br/portal/index.ph p?option=com_content $\&$ view $=$ article $\&$ $\underline{\mathrm{id}=30253}$. Acesso em: 15 Ago. 2019.

MBEMBE, Achille. Necropolítica. São
Paulo: Artes \& Ensaios - revista do ppgav/eba/UFRJ, n. 32, dezembro de 2016. . Crítica da razão negra.

Revisão de L. Baptista Coelho. "Critique de la raison negre". Paris, traduzido por Marta Lança, Lisboa, $3^{\text {a }}$ edição, setembro 2014.

The age of humanism is ending. Mail e Guardian, South África. Disponível em https://mg.co.za/article/2016-12-22-00the-age-of-humanism-is-ending. Acesso em: 03.jan.2018.

NAZARÉ, F. C. A Política da Morte: Uma Análise Sobre a Subjugação do Direito a Vida Pelo Poder Estatal, Sob o Aporte Teórico de Achille Mbemb. Complexitas - Rev. Fil. Tem. Belém, v. 4, n. 2, p. 19-26, jul./dec. 2019. Disponível em: http://www.periodicos.ufpa.br/index.php/complexitas/article/view/8051>. Acesso em: 30 de janeiro de 2020. 